\begin{tabular}{|c|c|c|}
\hline $\int_{t, 15} 3019992$ & ATA TRANSMITTAL & 1. EDT 156486 \\
\hline $\begin{array}{l}\text { 2. To: (Receiving Drganization) } \\
\text { TWR/TFP }\end{array}$ & $\begin{array}{l}\text { 3. From: (originating Organization) } \\
\text { Consequence Analys is ( } 8 M 400)\end{array}$ & $\begin{array}{r}\text { 4. Related EDT No.: } \\
\text { N/A }\end{array}$ \\
\hline $\begin{array}{l}\text { 5. Proj./Prog./Dept./Div.: } \\
\text { TWRS }\end{array}$ & $\begin{array}{l}\text { 6. Cog. Engr.: } \\
\text { J. E. Kelly }\end{array}$ & $\begin{array}{r}\text { 7. Purchase order No.: } \\
\qquad N / A\end{array}$ \\
\hline \multirow{2}{*}{\multicolumn{2}{|c|}{$\begin{array}{l}\text { 8. Originator Remarks: } \\
\text { Approval/Release }\end{array}$}} & $\begin{array}{l}\text { 9. Equip./Component No.: } \\
\text { N/A }\end{array}$ \\
\hline & & $\begin{array}{c}\text { 10. System/Bldg./Facility: } \\
N / A\end{array}$ \\
\hline \multirow[t]{3}{*}{ 11. Receiver Remarks: } & & $\begin{array}{c}\text { 12. Major Assm. Dwg. No.: } \\
\text { N/A }\end{array}$ \\
\hline & & $\begin{array}{l}\text { 13. Permit/Permit Application No.: } \\
N / A\end{array}$ \\
\hline & & $\begin{array}{l}\text { 14. Required Responsē Date: } \\
\text { N/A }\end{array}$ \\
\hline
\end{tabular}

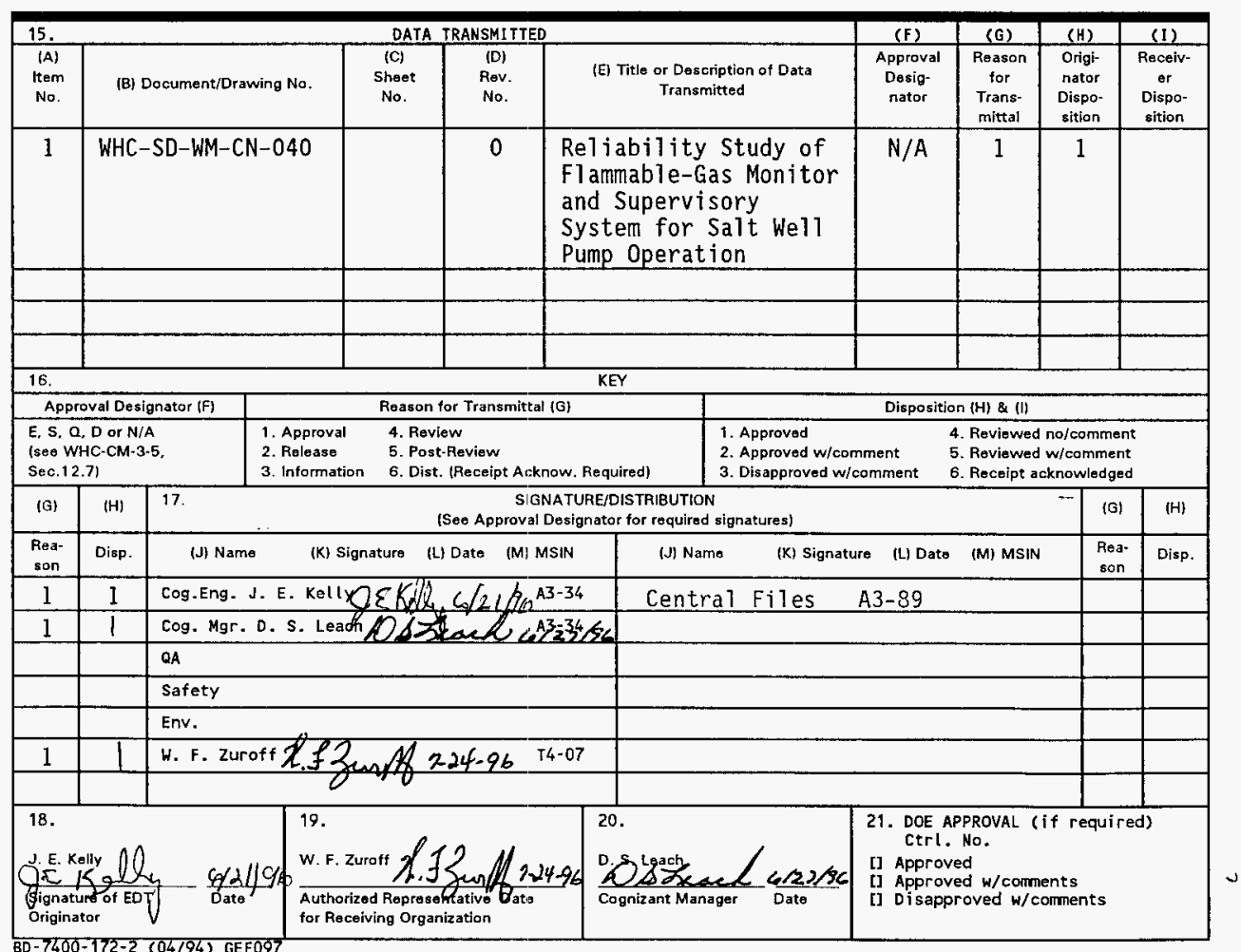




\section{Reliability Study of Flammable-Gas Monitor and Supervisory System for Salt Well Pump Operation}

\section{J. E. Kelly}

Westinghouse Hanford Company, Richland, WA 99352

U.S. Department of Energy Contract DE-AC06-87RL10930
EDT/ECN: 156486
UC: 610
Org Code: $8 M 400$
Charge Code: $N 1737$
B\&R Code: EW3120071
Total Pages: 7

Key Words: Reliability, Flammable-Gas Monitor, Saly Well Pump Operation

Abstract: This report evaluates the reliability of a flammable-gas monitor for salt well pump operation.

TRADEMARK DISCLAIMER. Reference herein to any specific comercial product, process, or service by trade name, trademark, manufacturer, or otherwise, does not necessarily constitute or imply its endorsement, recommendation, or favoring by the United states Government or any agency thereof or its contractors or subcontractors.

Printed in the United states of America. To obtain copies of this document, contact: WHC/BCS Document Control Services, P.O. Box 1970, Mailstop H6-08, Richland WA 99352, Phone (509) 372-2420; Fax (509) 376-4989.
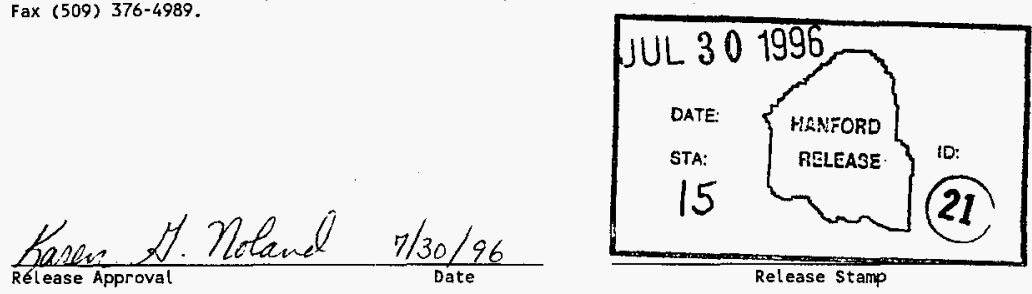

Approved for Public Release 
WHC-SD-WM-CN-040 Rev. 0

\subsection{PURPOSE}

Interim stabilization is the removal of pumpable liquids from Hanford's single shell radioactive liquid storage waste tanks to the newer double shell tanks. This project requires operation of a salt well jet pump in tank waste. It is possible that the waste in these tanks retains flammable gases (e. $\mathrm{g}$. hydrogen, methane, and ammonia) and oxidizers (e. g. nitrous oxide) created in the waste and for the resulting gas mixture to be released by the mechanical action of the pump. Since the salt well pump and other equipment/instruments in the pump pit are energized with electricity, combustion could occur. Westinghouse Hanford Company has procured flammable gas monitors to monitor for the presence of such gas. The salt well pump will be shut down if gas is present. TWRS Engineering Support has been asked to perform a reliability study of the Safety Class flammable gas monitor and supervisory system to be used in conjunction with the salt well pump operation. The units are being procured from Belhaven Applied Technologies. The intent of this study is to determine what must be done to show that the reliability is $99.9 \%$. It has been suggested that the study should be similar to Appendix Z of WHC, 1996, (referred to as Appendix $Z$ throughout). The Consequence Analysis Group has been asked to perform this reliability analysis. The Calculation Note below documents this analysis.

The following discussion provides a basis for understanding probabilistic calculations. All of the following discussion is quoted from IEEE, 1975.

Quantitative analysis uses what is known or assumed about the failure characteristics of individual component parts to predict the failure probability of the system. A mathematical model for system success is used as a function of some or all of the following: failure rates, repair rates, test intervals, mission time, system logic, and surveillance test schedule. In practice the validity of quantitative results may be limited by the quality and quantity of data; however, useful comparative results and sensitivity analyses do not depend on the availability of extensive data.

Mission Definition. A detailed description of what the system must do for success for the time interval or task of interest, and for the environmental conditions under which the system must perform is called the mission definition. There may be more than one function of interest, and each must have its own particular mission definition.

Reliability. Reliability is the characteristic of an item expressed by the probability that it will perform a required mission under stated conditions for a stated mission time. In the simplest case, repair is not allowed during the stated period of time. If redundant channels comprise a system, one or more channels may fail and may be repaired, provided there is no 
WHC-SD-WM-CN-040 Rev. 0

discontinuity of function. The exact ground rules for treating repair must be clearly delineated.

Common Mode. Effects that violate the assumed independence of component failures are called "Common Mode", "Systems Interactions", "Dependencies", and "Common Cause". A condition or event which causes multiple basic events is called a common cause.

\subsection{EQUIPMENT DESCRIPTION}

A tour was made of Belhaven Applied Technologies to observe the monitor. There are three parts to the monitor: a control valve cabinet, an electronics cabinet containing the programmable logic controller (PLC), and a gas sample pump. An air compressor in the salt well skid supplies compressed air to* drive the sample pump. The flammable-gas monitor will be located outside the dome of the tank. It uses a pneumatic pump to remove a sample of the dome atmosphere and monitor for flammable-gas. The pneumatic pump is quite reliable, but if it should fail so that there is too little flow or too much flow, it will shut down the monitor and salt well pump. The monitor has a supply of flammable gas and can initiate a self test. The Senior Engineer on the project is suggesting a self test every half hour. Bottled gas is contained in the cabinet. The test is performed by supplying a known quantity of gas in the stream and verifying the monitor sees it. With hourly tests, the bottle would last about two weeks. When the supply gas is low, the monitor senses it. For the purposes of this study, I wi1l assume a monthly test. The monitor itself operates like a wheatstone bridge in the middle of the sample flow. There are filters that remove moisture from the flow path. The filters are cylindrical in shape and the sample flow flows out the open end. Gas supplied from the calibration gas bottle is used to check for sensor drift and to do confidence loop tests for plugged lines and other system characteristics. The combustible gas module in its original configuration is attached to the bottom of the control valve cabinet. This module contains the flammable gas sensor and supporting electronics. The concentration of flammable gas in the sample steam is measured between 0 to $30 \% \mathrm{LFL}$. If the combustible gas module detects flammable-gas at a concentration higher than a preset value then the PLC sends a signal to the salt well pump interlock that shuts down pumping operations by isolating the electric power supplied to the pump pit. In the safety class unit, the shutdown feature will be independent of the PLC, and will be performed by separate electronic components.

Electronic components of this type are usually quite reliable and will not affect the outcome of this study.

\subsection{METHODOLOGY}

Appendix $Z$ presents the evaluation of a simple fault tree model. It estimates the unavailability of a flammable-gas monitor for salt well pump operation. This requires defining all of the events in a accident sequence. The reliability analysis documented in this calculation note utilizes the simple fault tree approach, but removes events that complete the accident. An accident includes all of the events that define the accident. In a 
reliability study, one wants to concentrate on the equipment being analyzed. Appendix $Z$ performs the following calculation:

$$
\begin{aligned}
F_{f} & =P \times P_{L F L} \times P_{i}=(1.0 E-5)(1.0 E+4)(5.0 E-2)(1.0 E-2)(1)=5.0 E-3 \times 1.0 E-2 \times 1 \\
& =5.0 E-5 / y r
\end{aligned}
$$

where $F_{f}$ is the frequency of ignition per year from an unrecognized monitor fault given only one monitor operating, $P$ is the probability per year that the flammable-gas monitor is down without being identified by the supervisory system as inoperable (which is the fraction of time that automatic pump shutdown is not available) and assuming that the events are independent, would be about $R \times P_{m d}, R=(F r) \times T=1.0 E-5 / h r \times 1.0 E 4 h, P_{\text {md }}=5.0 E-2$ demand, $P_{L F L}$ assuming a frequency of once per year for a gas release that results in concentration above the LFL, then the probability of any random 100-hour period having the LFL event called $P_{L F L}$, is about 100 hours $/ 10000$ hours or 1.OE-2, $P_{i}$ is the probability of ignition.

The frequency of $5.0 \mathrm{E}-05 / \mathrm{yr}$ assumes one monitor. For two monitors (redundant and diverse), the probability is not multiplicative; it only decreases by oneorder of magnitude. This is because there is some amount of common mode failure even though it has been specified as redundant and diverse. The word, "diverse" was used in Appendix $Z$. In terms of reliability, the desire is to have two units that do the same thing, but in a different manner. In this manner, there is no possibility of having the two units fail in the same way. Belhaven Applied Technologies has indicated that the redundant flammable-gas monitor will be manufactured by a different vendor. Therefore, manufacturing errors cannot cause a common mode failure, only common design. We have accounted for some common mode in our calculations and it is conservative. For two monitors the frequency is $5.0 \mathrm{E}-06 / \mathrm{yr}$. Both calculations of $F_{f}$ are frequencies. The frequencies must have the frequency element removed so that they are probabilities or unavailabilities. Then the complement which is the reliability may be found.

\subsection{ASSUMPTIONS}

Appendix $Z$ assumed that the mean unrecognized downtime for a failure is 100 hours. It further assumed that the pump or other possible ignitor, while /operating, is a continuous ignition source for gas above the LFL. The probability of an ignition $P_{j}$, is assumed as 1.0. Let the probability that the flammable gas is above the LFL sometime during the unrecognized downtime of the monitor be $P_{L F L}$. Appendix $Z$ also assumed a frequency of once per year for a gas release that results in a concentration above the LFL, then the probability of any random 100 -hour period having the LFL event called $P_{L F L}$, is about;

$$
\begin{aligned}
& P_{\mathrm{LFL}}=100 / 10000 \text { or }, \\
& P_{\mathrm{LFL}}=1.0 \mathrm{E}-2
\end{aligned}
$$


WHC-SD-WM-CN-040 Rev. 0

For the purposes of this reliability study assume that the $P_{\text {LFL }}$ has a probability of one so that the emphasis will be on the flammable-gas monjtor failure (MF) and supervisory system failure (SSF).

LANL used 10,000 hours in a year in their calculations for simplicity and conservatism. We will use 8760 hours because that is what is actually in a year. Further assume the monitor is tested daily (24 hours), and the supervisory panel is tested monthly (720 hours) to assure that it removes the necessary electrical power. Presently per Belhaven Applied Technologies, a blast of known gas is applied to the flammable gas monitor and verified to be sensed, but the supervisory system is not tested or checked. To use the reliability numbers given below, the salt well pump should be shutdown by the supervisory system to verify the supervisory system functions as designed. Assume further that the test takes less than three minutes a month to shutdown and start the salt well pump. This would place a tau of $720 / 2$ (360) hours rather than 8760 hours or 10000 on MF. Tau is defined as the mission time or test interval (see page 1). The reason for the lower tau is that when we test monthly, either the MF functions or we shutdown and repair it. After a test, the MF can fail immediately or just prior to the next test. The times of 0 and 720 hours are averaged and found to be 360 hours. The SSF will have 0.1 total demands placed on it per year (as defined in Section 4).

\subsection{INPUT DATA}

The input data comes from Appendix $Z$ and is as follows:

$\lambda(M F)=1.0 \mathrm{E}-05 / \mathrm{hr}=$ failure rate of the $\mathrm{flammable-gas}$ monitor

$\lambda(S S F)=5.0 E-2 /$ demand, and the demands are $1.0 \mathrm{E}-1 / \mathrm{yr}=$ failure rate of the supervisory system

$\mathrm{T}(\mathrm{SSF})=$ mission time for the supervisory system

$\mathrm{P}=\lambda(\mathrm{SSF}) \times \mathrm{T}(\mathrm{SSF})=5.0 \mathrm{E}-2 \times 1.0 \mathrm{E}-1 / \mathrm{yr}=5.0 \mathrm{E}-3 / \mathrm{yr}$ for $10000 \mathrm{hrs}$ and

$5.0 \mathrm{E}-2 \times 3.65 \mathrm{E}-3$ for $365 \mathrm{hrs}$

$P_{L F}=100$ hours $/ 10,000$ hours $=1.0 E-2$ and 1 for reliability studies

P(RPGIS) $=1.0$

1 year $=10,000$ hours for LANL's study and 8760 hours for the reliability study

$P_{i}=1$

The $\lambda$ (MF) and $\lambda$ (SSF) were obtained from GRE 1981. Monitors used in Liquified Natural Gas Facilities are to detect leaks much like the purpose here to detect levels of gas. They are not always in a flammable-gas atmosphere.

\subsection{CALCULATIONS}

Using the LANL equation, but substituting a probability of one for the frequency yields the following:

$$
\begin{aligned}
P_{f}=P \times P_{L F L} \times P_{i}= & \lambda(S S F) T(S S F) \times P_{1 F L} \times P_{i}= \\
& =\left[(5.0 E-2)(1.0 E-5) 365^{1}\right] \times 1 \times 1=
\end{aligned}
$$




$$
\begin{aligned}
& \text { WHC-SD-WM-CN-040 Rev. } 0 \\
= & (1.825 \mathrm{E}-4) \times 1 \times 1 \\
= & 1.825 \mathrm{E}-4
\end{aligned}
$$

This result is for one monitor. For two monitors (redundant and diverse), the probability is not multiplicative; it decreases by one-order of magnitude. For two monitors the probability of failure $1.825 \mathrm{E}-5$. This would result in a reliability of 0.9998175 and 0.99998175 respectively for one monitor and two monitors. See page three for a discussion of the word "diverse".

\subsection{RESULTS}

By testing the monitor and supervisory system once a month, one can obtain $99.98175 \%$ reliability with one monitor and $99.998175 \%$ reliability with redundant but diverse monitors.

\subsection{CONCLUSIONS}

By applying a monthly test interval, one can surpass the reliability requirement stated in Section $1(99.9 \%)$. In reliability terms, one monitor tested monthly is evaluated as three $9 \mathrm{~s}$. Adding the test and a redundant and diverse (see page 3) monitor more would be evaluated as four 9s.

\subsection{REFERENCES}

IEEE, 1975, Guide for General Principles of Reliability Analysis of Nuclear Power Generating Station Protection Systems, IEEE 352-1975, American National Standard published by The Institute of Electrical and Electronics Engineers, Inc., New York, New York.

WHC, 1996, A Safety Assessment For Salt Well Pump Operations In Tank 241-A-101: Hanford Site, WHC-SD-WM-SAD-034, Rev. 0, Appendix Z, LoS Alamos National Laboratory, Los Alamos, New Mexico.

WHC, 1996, A Safety Assessment For Salt Well Pumping in Single-She7l Tanks, WHC-SD-WM-SAD-036, Rev. 0, Appendix S, LoS Alamos National Laboratory, Los Alamos, New Mexico.

GRE, 1981, Development of an Improved LNG P7ant Faj7ure Rate Data Base, Gas Research Institute, Applied Technology Corporation Document. 


$$
\text { WHC-SD-WM-CN-040 Rev. } 0
$$

\section{CHECKLIST FOR PEER REVIEW}

Document Reviewed:Reliability Study of Flammable-Gas Monitor and Supervisory System for Salt We11 Pump Operation

Scope of Review:

$\frac{\text { Yes No NA }}{\text { [ ] [ ] [V] * }}$

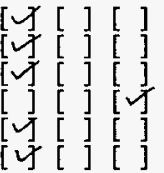

[U] [ ] [ ]

[U] [ ] [ ]

[V [ ] [ ]

[ ] [ ] [ [ ]

[ $][$ ] [ ]

[ ] [ [ ] [ [ ]

[ひ [ ] [ ] .

[Y [ ] []

[ ] [य] *

Previous reviews complete and cover analysis, up to scope of this review, with no gaps.

Problem completely defined.

Accident scenarios developed in a clear and logical manner.

Necessary assumptions explicitly stated and supported.

Computer codes and data files documented.

Data used in calculations explicitly stated in document.

Data checked for consistency with original source information as applicable.

Mathematical derivations checked including dimensional consistency of results.

Models appropriate and used within range of validity or use outside range of established validity justified.

Hand calculations checked for errors. Spreadsheet results should be treated exactly the same as hand calculations.

Software input correct and consistent with document reviewed. Software output consistent with input and with results reported in document reviewed.

Limits/criteria/guidelines applied to analysis results are appropriate and referenced. Limits/criteria/guidelines checked against references.

Safety margins consistent with good engineering practices.

Conclusions consistent with analytical results and applicable limits.

Results and conclusions address all points required in the problem statement.

Format consistent with appropriate NRC Regulatory Guide or other standards

Review calculations, comments, and/or notes are attached.

\section{[Y[ ] [ ] Document approved.}

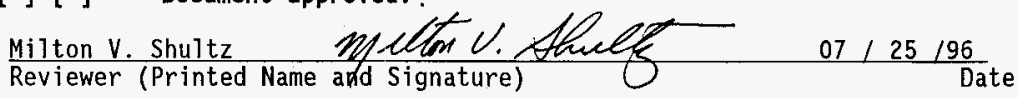

* Any calculations, comments, or notes generated as part of this review should be signed, dated and attached to this checklist. Such material should be labeled and recorded in such a manner as to be intelligible to a technically qualified third party.

\section{6 of 6}

